\title{
Congressos e Reuniões Científicas
}

14th IUPAC Conference on Chemical Thermodynamics

Osaka, Japão

Agosto, 25-30, 1996

Prof. Michio Sorai

Executive Secretary of ICCT-96

Microcalorimetry Research Center

Faculty of Science

Osaka University

Toyonaka, Osaka, Japão

Tel.: +(81) 6-850 5523

Fax.: +(81) 6-850 5526 ou 5288

email.: icct96@chem.sci.osaka-

u.ac.jp

20th IUPAC Symposium on the Chemistry of Natural Products

Chicado, Illinois, USA

Setembro, 15-20, 1996
Mary Giacomoni

Dept. Chemistry

University of Chicago

5735 South Ellis Avenue

Chicago, Illinois, 60637 USA

Tel.: 1-312-702 3173

Fax.: 1-312-702 7052

email.:

MFG@RAINBOW.UCHICAGO.EDU

IUPAC International Symposium on Macromolecular Condensed State

Pequim, China

Agosto, 20-25, 1996

Prof. Xigao Jin,

Institute of Chemistry

Chinese Academy of Sciences

PO Box 2709
Pequim 100080

China

Tel.: +8610-2564829

Fax.: +8610-2569564

email.: huangsl@rose.cnc.ac.cn

IUPAC Chemrawn IX

Conference on Sustainable

Production, Use, Disposal and

Recycling of Material and the Role

of Advanced Materials in

Sustainable Development

Seul, Coreia

Setembro, 1-6. 1996

Organizing Committee $\&$

Secretariat

IUPAC CHEMRAWN IX

Tongwon, B/D 6th Fl,

128-27 Tangju-dong, Chongno-ku
Seul, Coreia

Tel.: +82(2)-739-4521

Fax.: +82(2)-739 6187

email.: 5502833@MCIMAIL.COM

\section{9th IUPAC International}

Congress on Pesticide Chemistry

Londres, Inglaterra

Agosto, 2-7, 1998

Dr. John F. Gibson

9th IUPAC International Congress

on Pesticide Chemistry

The Royal Society of Chemistry

Burlington House

London WIV 0BN, UK

Tel.: 44-171-437 8656

Fax.: 44-171-734 1227

\section{Relocation \\ of IUPAC \\ Secretariat}

The International Union of Pure and Applied Chemistry IUPAC grew out of the international recognition of a need for standardisation in chemistry. It is accepted that standardisation of weights, measures, names and symbols is essential to the well-being and continued success of science as well as industry. Indeed it is essential for the smooth development and growth of international trade and commerce. It was this desire for international cooperation amongst chemists, and the wish to facilitate the work of the international, but fragmented, chemistry community that was one of the earliest characteristics of the Union.

At a meeting of the Executive Committee of IUPAP in Oxford, 20-21 April, 1996, the future location of the IUPAC Secretariat were carefully considered.

The Executive Committee decided to accept the proposal put forward by the US National Committee for IUPAC, and to move the Secretariat to Research Triangle Park, North Carolina, US, when the current Executive Secretary, Dr. Mo Williams, retires at the end of April 1997.

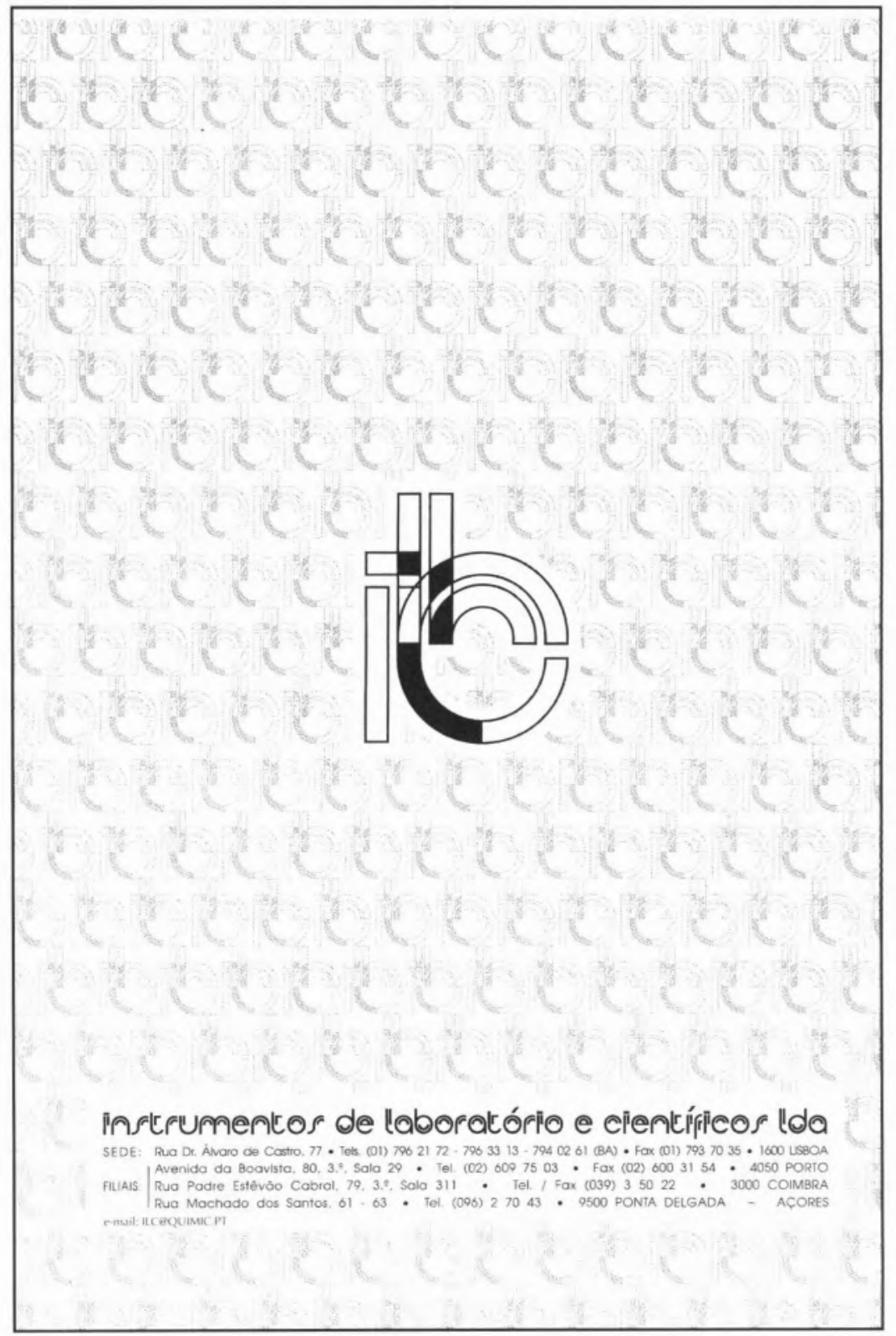

